\title{
Exploring the scope for Normalization Process Theory to help evaluate and understand the processes involved when scaling up integrated models of care: a case study of the scaling up of the Gnosall Memory Service
}

A paper for the Journal of Integrated Care - August 2020

Michael Clark, Associate Professorial Research Fellow, Care Policy Evaluation Centre, London School of Economics and Political Science, Houghton Street, London WC2A 2AE.

M.C.Clark@lse.ac.uk (Author for correspondence).

David Jolley, Personal Social Services Research Unit, University of Manchester, Manchester, UK

Susan Benbow, University of Chester, Chester, UK

Nicola Greaves, Gnosall Surgery, Gnosall, UK

Ian Greaves, retired GP formerly of Gnosall Surgery, Gnosall, UK

Author Biography:

Michael works as an Associate Professorial Research Fellow at CPEC, LSE. He has previously worked in several research and research management posts at local, regional and national levels.

Acknowledgements and disclaimer: Michael provided independent input in to the work reported here. David, Susan, Nicola and lan have been involved in establishing the Gnosall dementia service discussed in the paper and offered and provided some support to the roll out discussed, but were not closely involved in or responsible for this programme. We are very grateful to those who helped us understand the roll out, though the views expressed here are entirely those of the authors.

\begin{abstract}
Purpose - The scaling up of promising, innovative integration projects presents challenges to social and health care systems. Evidence that a new service provides (cost) effective care in a (pilot) locality can often leave us some way from understanding how the innovation worked and what was crucial about the context to achieve the goals evidenced when applied to other localities. Even unpacking the 'black box' of the innovation can still leave gaps in understanding with regard to scaling it up. Theory-led approaches are increasingly proposed as a means of helping to address this knowledge gap in understanding implementation. Our particular interest here is exploring the potential use of theory to help
\end{abstract}


with understanding scaling up integration models across sites. The theory under consideration is Normalisation Process Theory (NPT).

Design/methodology/approach - The article draws on a natural experiment providing a range of data from 2 sites working to scale up a well-thought-of, innovative integrated, primary care-based dementia service to other primary care sites. This provided an opportunity to use NPT as a means of framing understanding to explore what the theory adds to considering issues contributing to the success or failure of such a scaling up project.

Findings - NPT offers a framework to potentially develop greater consistency in understanding the roll out of models of integrated care. The knowledge gained here and through further application of NPT could be applied to inform evaluation and planning of scaling-up programmes in the future.

Research limitations - The research was limited in the data collected from the case study; nevertheless, in the context of an exploration of the use of the theory, the observations provided a practical context in which to begin to examine the usefulness of NPT prior to embarking on its use in more expensive, larger-scale studies.

Practical implications - NPT provides a promising framework to better understand the detail of integrated service models from the point of view of what may contribute to their successful scaling up.

Social implications - NPT potentially provides a helpful framework to understand and manage efforts to have new integrated service models more widely adopted in practice and to help ensure that models which are effective in the small scale develop effectively when scaled up.

Originality/value - This paper examines the use of NPT as a theory to guide understanding of scaling up promising innovative integration service models.

Keywords integration, older people, dementia, primary care, scaling up, Normalization Process Theory

Paper type conceptual paper and case study evaluation

\section{Introduction}

Integrated care is a widely discussed central concept in health and social care policy, especially as a solution to the challenges faced in balancing rising demand and scarce resources (Dickinson 2014). It remains a continuing policy imperative, albeit one that is elusive conceptually and empirically (Stokes, Checkland, \& Kristensen 2016; Erens et al. 2016; Goddard \& Mason 2016; National Audit Office 2017; Humphries 2015; Exworthy, Powell \& Glasby 2017). 
There is some understanding of the broad enablers of high-quality integrated care (e.g. Cameron et al. 2012; Ham \& Walsh 2013), but there is less certainty about the details of what works in what contexts (Sadler et al. 2018). In particular, we are far from sure of the factors that help/hinder more widespread adoption of specific, promising, innovative integrated care models, just as with many new, complex technologies (Greenhalgh et al. 2017).

Several overlapping concepts are used to understand processes involved in the wider adoption of innovations, including diffusion, dissemination, scaling up, scaling out and implementation (Shiell-Davis 2015). Here we shall discuss scaling up of innovations, by which we mean a directly guided effort to effectively put into a system something new which has shown evidence of promise in other geographical or service areas but which is new to that particular system.

Potentially flexibility in implementing models of care assists with scaling up (e.g. Naylor \& Charles 2018), but this requires evidence of what about each new care model can be adapted, in which circumstances and in what ways. One consideration is opening these 'black boxes' of the models of care to better understand effective elements, whilst another is better understanding the scaling up process itself (e.g. Goodwin 2013; van der Klauw et al. 2014; Dickinson 2006). Unpacking models of care is the subject of, for example, process evaluations in clinical trials. Our focus here, however, is on how to better understand the process of scaling up of innovative integrated care models that have developed an evidence to support their cases.

There is a wide-ranging literature on scaling up of innovations, but still with significant gaps in the evidence (Shiell-Davis 2015). Scaling up in the NHS continues to be a fraught, complex issue, frequently causing consternation and, hence, one in need of more robust investigation and evidence (Collins 2018). Only recently in relation to an ambitious programme in England to develop transformative approaches to care, the Vanguard programme, it was recognised that spreading promising local models across the NHS remains a challenge (Naylor \& Charles 2018).

Scaling integrated care models adds further inter- and intra-organisational complexity to understanding and managing the process of adoption of innovations. Whilst frameworks have been developed to guide scaling up health models (e.g. Naylor \& Charles 2018, World Health Organization 2010, Jeffcott 2014, NHS England Sustainable Improvement Team nd), these are more narrative than theoretically driven. It is worth, then, investing in exploring the use of theories to help us better understand the process of scaling up integrated care. A cautious approach to this undertaking would be sensible, as there is a wide array of theory to consider, particularly drawing from the evolving disciple implementation science (Damschroder 2020; Nilsen 2015). Before investing large sums of research funding in major projects investigating the scaling up of integrated care grounded in specific theoretical 
perspectives, we need a careful consideration and pilot testing of the most promising theoretical approaches. This paper seeks to contribute to this process.

The model of diffusion of health care innovations (Greenhalgh et al. 2004), is one such example of a potential perspective to help us understand scaling up as something more complex than a simple linear process from innovation to adoption and scaling up. Models of diffusion are, though, not so strong at helping us understand the processes by which new practices are made workable in local contexts and become routine or normal practice (May 2006).

The development of 'theories of change' (TOC) for innovations to understand how they work (e.g. Ferrara \& Moro 2016) can provide powerful insights to understand the operations of a complex model of care or intervention. However, these can be specific to the context of the original evaluation and, in themselves, may not provide strong insights into implementation and scaling up processes. Similarly, realist informed evaluations (Pawson and Tilley 1997) of complex interventions can help understand the contexts, mechanisms and outcomes of a model of care, but may leave gaps in our understanding of how to scale up from the original site(s).

Actor Network Theory (ANT) (Latour 2005) is a broader social theory concerning the adoption of innovations that has been used in health care (e.g. Cresswell, Worth \& Sheikh 2010). However, the theory has controversial elements, notably equating human actors with objects in terms of agency (May \& Finch 2009).

A theoretical perspective focused on the intention of people to do or not do something may specifically tell us why a model of care is adopted or not. One such approach is the Theory of Planned Behaviour (TPB) (Ajzen, 1991), which has been demonstrated to help in part explain the take up of changes in health care (e.g. Hanbury, Wallace \& Clark 2009). However, TPB generally explains only a modest proportion of the variation in actual behaviour (May \& Finch 2009) and there are calls to avoid using it in some evaluative research because of its limited impact (Moore \& Evans 2017). Again, it is not clear that TPB is a strong candidate theory to understand scaling up.

In this context, we discuss here the use of a theoretical understanding of how new practices do or do not become accepted, namely Normalisation Process Theory (NPT) (May 2006; May \& Finch 2009). This theory was seen as having potential merit in the context of exploring the scaling up of innovative integrated care models, as it combines perspectives on individual agency with some consideration of context. Changing practice involves, amongst other things, sensemaking concerning the expected benefits and risks of the new practices compared to established ones (Kitson 2008). Hence, exploring a theory which explicitly incorporates consideration of individual and collective agency is a sensible place to start in understanding scaling up integrated care models. We discuss NPT in more detail below. 
To examine NPT in the context of understanding scaling integrated care, we used a natural experiment, namely the roll out of an existing model of dementia care in primary care. We begin by briefly discussing this model of care and its history to help understand the process of scaling up we examine later. The lead author (MC) has been an independent observer of the developments described below throughout, whilst the others have had various embedded connections with the Gnosall model. No authors had direct responsibility for the scaling up pilot discussed below, but at times met with individuals who were responsible and some of the discussion below draws on these interactions.

\section{The Gnosall model of integrated, primary care-based dementia care}

\section{The context}

\section{i) Innovating in dementia care}

In the context of an ageing population (Foresight 2016) dementia is expected to continue to grow in terms of the number of people it affects, and as a challenge for societies (Livingston et al. 2017; Ahmadi-Abhari et al. 2017; Knapp et al. 2014; WHO 2012). There is a need for new models of care to meet these rising challenges and to improve dementia care (Gilburt et al 2014; Royal College of Psychiatrists 2011; Knapp et al. 2014; Parliamentary and Health Service Ombudsman 2016; Cornwell J 2012). A series of national initiatives has sought to stimulate these processes (e.g. Department of Health 2009, 2012 \& 2015). Better integration centred on primary health care is one possible area for innovation and improvement (Clark et al. 2013; Greaves et al. 2013; Meeuwsen et al. 2012), and particularly for improving post-diagnostic support, but barriers between services present challenges to achieving this.

One promising model of primary care-based, integrated dementia care was developed in Gnosall, a village in Staffordshire, England (Clark et al. 2013; Greaves et al. 2013). The service bridges geographical and knowledge gaps between secondary and primary care to help people living with dementia and their families. A Consultant Old Age Psychiatrist is employed part time in the primary care practice along with an Elder Care Facilitator (ECF) to work directly with the patients, their families and communities. The model was seen to lead to clinical improvements and was estimated by local health authorities to lead to savings for the local health economy of $£ 450,000$ per year might be expected under previous care arrangements, largely as fewer people were admitted to secondary care, and many of those who were experienced speedier and more supported discharge to home (House of Commons Health Committee 2014). The Gnosall model has been promoted as a promising one for improving dementia care (Oliver, Foot \& Humphries 2014; Hawkins 2015).

iii) Scaling up the Gnosall model

Convinced by the accumulating evidence from Gnosall, two Clinical Commissioning Groups (CCGs - primary care-led components of the NHS responsible for purchasing health care 
services in their localities) began scaling up the integrated model of memory service to their primary care practices in January 2014 as a 2-year long pilot project. The model deployed was based on the original but with some local adaptations seen by participating organisations as necessary to suit their context. We discuss these key differences next and consider their implications for the case study sites as we discuss the application of NPT to understanding the experience of scaling up the model to the two CCGs .

A key difference to the original site was an increase in the number of organisations responsible for different aspects of the scaling up, where the Gnosall site had been wholly contained within the village's primary care practice. In the scaling up to two new, much larger areas (CCGs, for example, include many primary care practices rather than the one in Gnosall), the CCGs were responsible for commissioning the model, whilst another body, a Federation of GPs, was responsible for its delivery. The Federation subcontracted the specialist dementia care element to their existing provider mental health NHS Trust. A local hospice employed the ECFs (who had slightly different titles in the scaling up, but for ease of understanding we will use the original Gnosall title here). These more complex organisational arrangements were in part driven by the larger geographical scale of the implementation, but also by reforms put in place by the Health and Social Care Act 2012.

Another distinctive variation from the Gnosall model was clinical. It was agreed that the role of the consultant psychiatrist could be undertaken by other experienced mental health professionals, notably psychiatric nurses. The nurses did still refer to consultant psychiatrists in some cases. This was not viewed at initiation by participating organisations as potentially problematic to successful wider scale implementation, though concern was expressed by some connected with the Gnosall and scaling up sites that integration of clinical practice was not as complete as in Gnosall.

We also note that the Gnosall history was one of being a local endeavour by a group of colleagues with a shared understanding and desire to improve care, yet the scaling up was conducted in an environment of greater political expectations, particularly with national NHS targets to improve dementia diagnosis rates. This allowed the Gnosall developmental process to be experimental, exploratory at times, and organic, whilst the scaling up was more tightly managed in terms of, for example, timescales and monitoring of politicised diagnosis rates in primary care practices.

The process of scaling up to the CCG sites was, in broad terms:

- January 2014 - Mobilisation - the elements of the service were put in place across the CCGs. A steering group oversaw implementation, with a programme manager, and regular analysis of key performance data. Challenges with recruiting ECFs and developing their role were encountered and addressed. Mobilisation was seen to go well. 
- Mid-point January 2015 - Bedding in - with positive signs such as improving diagnosis rates across the CCGs and encouraging feedback from people involved, the decision was made to continue to the second year of the planned implementation. Managing prescribing and uncertain diagnoses were emerging concerns but did not dent confidence in continuing.

- December 2015 - decision on continuing - toward the end of the planned two years of scaling up commissioners had to decide whether or not to continue with it across the two CCGs. To assist their decision a range of information was available to them, as discussed below.

During this process, we had opportunities to keep informed about progress and discussions about the future of the model. Some of us had opportunities to be engaged with those managing or being actively involved in the frontline of the scaling up and periodically we saw the performance data being used to monitor the process.

As we became aware that the decision on whether or not to continue with the model across the CCGs was going to be finely balanced we thought it a good opportunity to explore to what extent NPT might help to understand the scaling up process, how people were perceiving the model and whether it was becoming accepted (normalised). The intention as this stage was to explore the potential of NPT in helping develop a more theory-led understanding of the process of scaling up integrated care models. We were not aiming for an evaluation of the care model nor of the process of scaling up.

\section{Normalization Process Theory}

NPT provides a mid-level analytical framework to help understand how and why practices become normalized and embedded (or not) in everyday work (May 2006; May et al. 2007; Gask 2008). It concerns people's individual and collective agency when adopting new work practices.

There are 4 constructs to the NPT framework:

1. Coherence - the individual and collective 'sense-making' work that people do to decide if a new practice is worth persevering with;

2. Cognitive participation - the relational work that participants in the new practices undertake to build a sustainable sense of a community of practice;

3. Collective action - the operational work undertaken to enact the new practices;

4. Reflexive monitoring - the appraisal work to understand how the new practice is affecting those adopting the new practices and others involved.

These form an interlinked set of communal and individual processes. Each construct has four components, which we will discuss later as we apply NPT to understanding the scaling up of 
the dementia service. The constructs have been seen to interact in diverse ways in different settings related to, for example, whether the focus is on feasibility studies or later stages of implementation (May et al. 2018). This potentially provides for a powerfully flexible theory to understand processes of normalization in different contexts (May et al. 2018).

NPT is proving productive in understanding the adoption of a large range of complex practices (McEvoy et al. 2018; May et al. 2018). It has been applied to, for examples, adoption of a collaborative care model for depression in primary care (Coupe et al. 2014), implementation of tele-dermatology (Finch 2008), and implementation of guidelines in hospitals (May, Sibley \& Hunt 2014). It has also been applied to the longitudinal study of the more complex, policylevel implementation of revalidation procedures for medical practitioners (Tazzyman et al. 2017). One lesson from these applications of NPT is that a new practice might be experienced to work well in terms of some NPT constructs, yet still be seen to be inappropriate in the round and, hence, fail to become routinized in practice.

\section{Methods}

NPT has been applied methodologically in diverse ways including as a framework to organise specific questions in data collection, through to its application to analysis after data collection, with mixed approaches between the two (May et al. 2018). In this study we applied it in a mixed mode. We used existing data to help understand some aspects of what was happening in the local contexts in terms of the implementation of the Gnosall model, along with data from interviews that used NPT as a sensitising framework to organise questions. NPT was then used to guide the overall synthesising of all this data to understand what happened during the scaling up and what contributed to the final decision about whether or not to sustain the model of care across the CCGs.

A range of data was available to inform this local decision and we were provided with the data and gathered insights into how it was being understood. The data used in the CCGs included:

(1) Performance data related to the scaling up of the model - the most crucial data used here was for diagnosis rates for dementia in each of the practices across the CCGs. As noted, this was politicised data as it directly related to national targets to improve these rates. Overall across the two CCGs the diagnosis rates improved during the scaling up period. This was from base rates that were relatively low compared to national ones. As of March 2015, for example, CCG 1 reported that it needed to diagnose an additional 6 patients with dementia to meet their nationally set diagnosis rates, this with over 1053 patients having been placed on dementia registers in the practices. The CCG had the fourth highest diagnosis rate in its region of 22 CCGs; only 3 had reached the national target.

Significant variation existed, though, in the changes in rates of diagnosis achieved by individual practices. In CCG 1 as of March 2015, 11 practices had achieved the nationally set 
diagnosis rate, with 3 achieving 90\% of their estimated diagnosis rates. Yet 15 of the practices still had not achieved their estimated diagnosis levels, with the bottom 6 being below $50 \%$ set diagnosis rate. These patterns reflected similar experience in CCG 2 and, albeit with some improvements, remained during the course of the 2-year pilot with both CCGs improving but not every practice achieving its target rates of diagnosis. As national diagnosis rates were generally rising (Health \& Social Care Information Centre 2015; Mukadam et al 2014; Donegan et al. 2017) changes at our case sites in diagnosis rates cannot be directly attributed to the scaling up of the Gnosall model across the CCGs. Indeed, the GP we interviewed identified several other factors that contributed to recorded improvement, including better coding in practices and work that some GPs had started in care homes. He was clear, though, that the model was seen to be a factor in improving local diagnosis rates in many practices.

(2) Findings from a survey of GPs - one of the CCGs undertook a survey of their GPs to ascertain their views of the new model of dementia care, conducted after the new service model had been in place for about 18 months. 13 of the 14 practices in the area responded. Respondents seemed to understand and sign up to the new model, reporting that they understood and preferred it to the previous, secondary care-focused service. There was a mixed but essentially positive response to the nurse-led approach to the local scaling up of the model.

However, there were some negative responses concerning whether or not patients received timely diagnoses. Overall, the responding GPs were split in terms of whether or not they felt the new model was successful.

(3) Findings from a survey of patients and carers - both CCGs, undertook this survey around March 2014, conducted by the ECFs when they saw clients. Separate, short questionnaires for carers and patients were used, each asking about the process of care in the dementia service (e.g. were you given information) and their experience of the service (e.g. do you feel your views were taken in to account in care planning). 82 patients responded and 59 carers. Although not the most robust method for a survey, it gives insights into how people were experiencing the new care model and, crucially for this paper, this was information available to decision makers. On the whole people responded that the new service was beneficial and liked.

In our exploration of the use of NPT to understand the scaling up process we designed a semistructured interview schedule to supplement these locally available data. As noted, the interview schedule was underpinned by NPT but did not directly ask about its constructs (see table 1). Two key local informants were interviewed using the schedule as the final decision about continuing with the new model or not was approaching. One was a key GP in the area who was participating in operationalising the model, and, although he was not directly responsible for managing implementation of the service, he was also involved the levels of GP Federation (contracted provider responsible for overall delivery of the new model) and CCG (commissioner of the new service). As such, he had an all-round understanding of the 
model and the scaling up process and was well connected with others, especially GPs, who would be involved. The second interviewee was the manager of the ECFs. The ECF was the newest role introduced by the model of dementia care and was employed by a hospice but worked alongside existing primary health care practitioners and the psychiatric nurses, so it was important to try to examine scaling up from the perspective of the ECF manager.

Table 1: NPT as a basis for the interview schedule

\begin{tabular}{|c|c|}
\hline Constructs of NPT & Example interview questions \\
\hline Coherence & $\begin{array}{l}\text { Do you think that people across the area of } \\
\text { the roll out see a coherent model and } \\
\text { distinguish it from current ways of working? } \\
\text { Do you think that people collectively agree } \\
\text { about the purpose of the model? } \\
\text { Do you think that people individually } \\
\text { understand what the model requires of } \\
\text { them? } \\
\text { Do you think that people see a potential } \\
\text { value of the model for their work? }\end{array}$ \\
\hline Cognitive participation & $\begin{array}{l}\text { Do you think that there are clearly key } \\
\text { individuals driving the model and scaling up } \\
\text { forward? } \\
\text { Do you think that people agree that the } \\
\text { model should be part of their work? } \\
\text { Do you think that people buy in to the } \\
\text { model? } \\
\text { Do you think that people continue to } \\
\text { support the model? }\end{array}$ \\
\hline Collective action & $\begin{array}{l}\text { Do all people involved clearly perform the } \\
\text { tasks required by the model? } \\
\text { Do you think that people have trust in each } \\
\text { other's work and expertise in the model? } \\
\text { Do you think that work in the model is } \\
\text { appropriately allocated to participants? } \\
\text { Is the model adequately supported by the } \\
\text { participating organizations? }\end{array}$ \\
\hline
\end{tabular}




\begin{tabular}{|l|l|}
\hline Reflexive monitoring & $\begin{array}{l}\text { Do people get and use information about } \\
\text { the effects of the implementation of the } \\
\text { model? } \\
\text { Do people collectively and individually } \\
\text { assess the model as worthwhile? } \\
\text { Do people modify their work in response to } \\
\text { appraisals of the implementation of the } \\
\text { model? }\end{array}$ \\
\hline
\end{tabular}

In analysis, NPT formed the framework for trying to understand the final decisions of the CCGs as to whether to continue with the new model of service after the initial 2-year pilot. We wanted to see to what degree NPT could help us understand the situation leading up to this decision in terms of to what degree the dementia service was normalised in practice and how the final decision was made about whether or not to continue with the model was made. The decision of the CCGs after the two-year pilot was to cease operationalisation of the dementia service and replace it with an as yet undetermined different approach.

\section{Results}

We now examine the data, particularly that from the interviews, against the NPT framework and in the process elaborate further on the detail of NPT. We examine its potential in understanding why, in this case, the scaling up process did not seem to work as the integrated care model was not normalised in to practice. We will discuss each construct of NPT in turn and their components.

\section{i) Coherence}

Differentiation is the first of four components of the construct coherence and refers to being able to see a difference between the old and new practices. It is clear from the GP survey and the interviews that participants in the CCGs could mostly differentiate the new dementia care model from the old.

Specification of the new model of care in general seemed successful in the CCG. The ECF manager, for example, felt that most GPs had come to understand (and value) the work of the ECFs, despite being uncertain about this at the start. The GP interviewed suggested that colleagues on the whole understood the model of care and how it was intended to operate, as did the findings of the survey of practices in one CCG.

Some aspects of the new model, though, remained to be resolved even towards the end of the pilot. The ECF manager said, for example, that some GPs had misunderstood the role of ECFs and, although this was mostly clear at the end of the 2 years, some GPs still asked their ECF to do tasks not part of the role. The manager felt that as GPs and practices were all 
different, working with GPs to help them understand the work of ECFs would be an ongoing negotiation. This indicates that some aspects of sensemaking during scaling up of a complex integrated care model require continuing attention.

Communal specification in the scaling up seemed to result in a broadly shared idea of the new service at all levels from the CCG and steering group down to direct practice. Participating organisations also developed aspects of the new practices collectively in light of experience gained. The reports from our informal discussions and from the interviews were, for example, of good integration developing in most practices between GPs, ECFs and the secondary care psychiatric nurses.

Some difficulty with communal specification was reported at the interface of primary and secondary care, a recognised friction point in care systems generally. A key focus of this was achieving timely diagnoses for certain patients. GPs believed the new model would improve diagnosis for everyone, and it seems to have done so for many. However, where there was uncertainty about diagnosis, the secondary care dementia nurses would refer to their consultant psychiatrists at the hospital for diagnosis. This led to delay and generated some unanticipated friction and frustration between the supposedly integrated primary and secondary care elements.

Internalisation of new practices, the fourth component of coherence, as people attribute worth to new practices and take ownership, appears to have worked well in many instances and to have been progressing in others. From the data it would appear that many of the GPs were internalizing the new practices, and the interviewees felt the ECFs were doing the same. We lack direct data concerning the response of secondary care colleagues in terms of internalization. It would appear from the interview with the GP that the psychiatric nurses were seen as working well, and so we might assume they were mostly internalizing the new practices. We can be less certain about the consultant psychiatrists, but note that many of them remained geographically remote from the integration of secondary and primary dementia care that the Gnosall model was based upon.

From the evidence we saw there were processes to stimulate this internationalization. The steering group regularly provided evidence of progress (e.g. data on overall diagnosis rates). Additionally, we heard of informal processes such as personal discussions about progress and the impact of the new service. We were told in the interviews that the sense was that most participants saw value in the new model, but these informal processes of communication across the CCGs were also used to air a few disappointments about the scaling up, such as how uncertain diagnosis was managed.

\section{ii) Cognitive participation}

Cognitive participation, building a relational community of practice, includes the component initiation referring to enacting the new practices. In the scaling up there was high-level, 
formal agreement to implement and make resources available for the model amongst leaders of all the participating organisations. There were also clear arrangements in terms of formal and conventional foci of project initiation: e.g. steering group, implementation plan and governance arrangements. A significant group of front-line practitioners from all parties to the integration effort also worked to drive the model's implementation and development.

A second aspect of cognitive participation is enrolment, i.e. forming and organising how participants join the new practices. We do not have all details of how enrolment was activated for participants, but there was a high-degree of formal enrolment in the scaling up: GPs were engaged at many levels of the process, including as participants in the operationalisation of the model, though the GP we interviewed questioned whether some practices where diagnosis rates remained low had fully engaged; ECF roles were created and recruited to and were seen to be actively enrolled, exemplified in their negotiation of the role with GPs; and some secondary care staff were enrolled in new roles. We heard that many secondary care participants came to embrace the new model and sought to make it work.

It seems that where there were existing boundaries (geographical, organisational and professional) between primary and secondary care, this hindered enrolment as the boundaries were not fully broken. As noted, the issue of uncertain diagnosis seemed evidence of shortcomings on enrolment as it highlighted a failure to complete integration and sufficiently reduce boundaries.

Where boundaries did not exist prior to scaling up, i.e. between the new ECFs and primary care, the process of enrolment appeared to be helpfully more fluid and flexible, though not always smooth. We also heard that enrolment across the ECFs and the mental health trust was given attention and improved over the 2 years.

Perhaps part of this challenge of enrolment arose from insufficient attention being paid to the next component of cognitive participation, namely legitimation of the model, i.e. forming and organising shared beliefs about its legitimacy and active enrolment. As new staff the ECFs had to work hard individually and collectively to shape their role and establish its legitimacy. GPs had a clear role and base in the primary care model. It is not clear that all from secondary mental health care felt legitimacy about the model, nor about secondary care roles within it, though this area is in part a gap in our information.

Perhaps, when existing roles are adapted for a new integrated service, more ongoing attention has to be given to developing a shared sense of legitimacy about the new practices: old assumptions and boundaries may linger. In scaling up integrated care services this is potentially a significant and ongoing issue to attend to, especially for those having to make the biggest change in adapting their work to fit the new service.

Also, in terms of legitimation, it was not always clear what the expected goals of the scaling up were. Implementation of the roles within the model was one that was mentioned to us, 
but other criteria also implicitly or explicitly framed judgements at different times. Improving diagnosis rates and speeding up all diagnoses were two such issues framing some thinking about the value of the pilot, including by the GP interviewed, but not necessarily by everyone.

Similar experiences were witnessed with regard to activation: collectively keeping focused and engaged in enacting and evolving the new practice. ECFs were seen to be determined to make the new model work: delivering their part of the bargain and showing willingness to resolve teething problems like calculating and managing their caseloads across surgeries. In contrast it was not always clear that all GPs were devoted to making the model work well. Despite overall improvements, diagnosis rates in the CCGs remained variable across practices. The lack of clarity about roles led to delays in some diagnoses and may indicate some shortage of activation by key secondary care colleagues. We heard of positive experiences of the new service amongst many secondary care staff directly engaged with primary care and about their work, but the friction produced by, for example, managing the fact that the primarysecondary care interface was not more fully integrated ( as manifest in managing uncertain diagnoses and some areas of prescribing) may have undermined confidence in and commitment to it.

\section{iii) Collective action}

Collective action entails interactional workability, i.e. that work which participants do with each other and artifacts to operationalize new practices. We repeatedly heard of good examples of interactional workability from the outset of implementation and of improvements through evolving practices within the model of care as staff learnt, such as clarifying the work of and better supporting ECFs. The GP interviewed felt that the nurses undertaking the specialist mental health work in the new service integrated well and delivered a good service. However, he commented that aspects of the primary-secondary interface were not working as well as had been implicitly assumed at initiation of the model and that it was frustrating for GPs. He added that it proved difficult to resolve these areas of the model once it had been put in place. The ECF manager also said that the link to secondary care was the area of concern she sensed most disquiet about.

Also of note is that the interactional workability was not so clear at the governance level of the scaling up. There was felt to be a shared commitment across leaders in the CCGs, and a steering group governance structure, but it was not clear how to manage these to deliver refinements of the model once implemented. The interviewees both discussed how implementation of the model was affected to some degree by difficulties that GPs were having in working out how they operated in connection with the scaling up as individual practices and as one Federation. The continuing variability of diagnosis rates was noted as the most pointed illustration of disappointment with how effective these organisational were at addressing such problems: GPs were meant to be operating as one Federation to undertake the scaling up, but some individual GPs did not seem to fully engage nor to address their 
reported low diagnosis rates and the governance of the scaling up could provide no solution to manage this.

Relational integration is the work participants do to build confidence in, and accountability of, new practices. In the scaling up pilot, the evolving understanding between many of the GPs and ECFs demonstrated positive relational integration. Together they built confidence in each other, though it had to be continually worked at. Relational integration was felt to have improved greatly over the 2 years between ECFs and secondary care staff in primary acre, though secondary care beyond that remained remote and opaque to ECFs in a way that expressed as being mildly frustrating. As noted, points of friction in how the dementia service operated indicated that relational integration was not as complete as hoped for across the primary-secondary boundary.

The third aspect of collective action, skill-set workability, concerns the division of labour operationalised in enacting the new practices. In the scaling up there was some uncertainty about division of labour in the new service such as some GPs not always understanding the work of ECFs, but the relational integration between these two parts of the new model of service enabled this to be worked at.

There continued to be more significant difficulties in the division of labour between GPs and secondary care colleagues. For the most part this did not seem to be an issue between GPs and the mental health nurses in their practices. However, three issues were highlighted in the interviews as continuing concerns about who was responsible for things. We have already identified managing uncertain diagnoses and mentioned concerns over responsibility for prescribing some medication. A desire had been for GPs to take the lead on prescribing in a shared care model, but this had never been formalized, so some GPs prescribed and others didn't, which left some secondary care colleagues uncertain of the proper procedure.

The third issue of uncertainty about the division of labour in the new service was highlighted by the GP and concerned how much work GPs were expected to do prior to referral to secondary care colleagues for diagnosis. Some GPs were doing almost full assessments (e.g. memory and blood tests) before referring to their linked nurse, whilst others simply referred patients with possible dementia. Confusion over key aspects of the division of labour left some uncertain, caused delays and seems to have undermined confidence in the model as a whole amongst some, including, crucially, those deciding whether or not to sustain the service after the 2-year pilot.

In terms of contextual integration, by which resources are allocated and policies and procedures realised in practice, we have noted high level commitment in the participating organisations. Resources were gathered across the participating organisations to initiate the new service model. Some procedures remained to be resolved.

\section{iv) Reflexive monitoring}


The systematising component of NPT refers to forming and organising of knowledge about the effects of the new practices. The formal process of the steering group was the key focus for this, and its members routinely scrutinised a range of data about the scaling up. Focused on this group and the need to nationally report diagnosis rates, a systematic approach developed to review a range of information about the scaling up pilot.

Communal appraisal entails the collective work of participants to assess the impacts of the new model. In the use of routine data on diagnosis rates and the surveys of GPs and patients, we saw excellent examples of work to formally develop a shared appraisal. Additionally, operational data were used to improve how ECFs were deployed across practices. However, key evidence about time to diagnosis does not seem to have been formally aggregated and assessed across practices. This seems to have come to light through informal appraisal and discussion, but it formed an important input into the final decision-making.

These informal routes to communal appraisal appeared to play a significant part in undermining confidence in the model of care. The GP interviewed commented that, when some people identified issues they felt needed 'tweaking' with the dementia service, there was no clear means of acting upon these concerns. Consequently, he argued, it took too long to evolve the model and frustrations built up when people felt they were not being listened to. He said that at times it seemed as if the mental health trust and the Federation blamed each other for issues and could find no easy means of resolving differences.

Potentially crucial to the final decision to stop the service was the lack of clarity about the overall goal of the scaling up. Across the two CCGs there seemed to be a shared sense of the need to improve dementia care. There seemed to be scope, though, for this to be focused on a variety of specific issues over time and by different participants in the pilot. One such focus was the objective of improving diagnosis rates, given major prominence by national policy and monitoring. We also heard of other implicit objectives, such as developing the ECF role, improving timely diagnosis, developing prescribing practice, addressing variability in diagnosis rates, and testing new organisational arrangements (e.g. the role of the Federation). These more implicit goals most likely fed into communal appraisal of the scaling up pilot and the final decision to cease it, but there appeared to no formal means of aggregating data about them and/or forming shared judgements across the organisations involved.

The GP interviewed, for example, identified that the model was helping to improve diagnosis rates for the CCG as a whole and he felt there was general agreement that a primary carebased model of dementia care was progress. He remained concerned, though, about the variability in diagnosis rates across practices. In discussing this variability, he in part saw the new service as a test of the federated approach to collectivising GPs and seeking to standardise practice across them.

The third component of reflexive monitoring, individual appraisal, is the process by which individuals personally assess whether the effects of an intervention are worthwhile for 
themselves. Individual appraisal of the scaling up was uneven, with positive and frustrating experiences expressed. The informal, anecdotal individual appraisals of some frustrating aspects of the model may have exerted undue influence on the decision to cancel the service as they operated outside the formal accountability framework. When identifying challenges with satisfying GPs about ECFs, the ECF manager commented that it was important to intervene early before emotions built up and the 'chatter' about dissatisfaction grew too great. It was not clear that anyone from secondary care was being attentive to such frustrations, though this may reflect our lack of data from this part of the service.

Reconfiguration, or organizing changes in the ways new practices are enacted, was evident in the scaling up, including making resources available, deploying staff to new roles, and an early collective decision to reshape the original Gnosall model to fit local arrangements. Most notable on this last was placing nurses in the practices instead of consultant psychiatrists. The newest roles to the local system, the ECFs, were flexible and allowed time to adapt to deliver the new system of care. Despite this commitment to reconfiguration, it seemed that some existing boundaries between primary and secondary care proved difficult to remove and integrate as fully as in the Gnosall service.

\section{Discussion}

In applying NPT to this case study, we sought to examine the degree to which this theoretical perspective could help understand how a complex model of integrated care does/does not become normalised in practice. It is worth noting that in many ways the new service model became routinised in local practice. The model was successfully run across the two CCGs for two years. There was greater integration of secondary care nurses working in primary care alongside newly recruited ECFs, and the latter role was seen to be operating so well that some GPs desired similar colleagues for working with patients with other conditions. Diagnosis rates increased across the CCGs and there was satisfaction with the new service amongst many stakeholders, including patients and carers.

So, how did this successful part of the story come about and how can NPT help us to understand it? In most aspects the scaling up of the Gnosall model to a wider geography and network of organisations adopted an approach in line with good advice to manage a large implementation programme (Leutz 2005) e.g. formal management plans and processes and good leadership. These management arrangements and their interactions in the complex process of scaling up can all be understood under the framework of NPT and interactions between and overlaps across the components of NPT could be identified in examining the scaling up.

Similarly, NPT helps us with a focus on coherence and understanding its place in normalisation of scaled up services. The dementia care model had good foundations for coherence from 
the Gnosall development, and managers collaboratively agreed modifications to fit local contexts and had discretion to evolve details of the model (e.g. deployment of the ECFs across practices). One continuing debate with regard to scaling up processes concerns standardisation versus flexibility of new interventions, with one perspective being to understand standardisation of function rather than form (Hawe, Shiell \& Riley 2004). In the case study sites, agreement about adapting a key aspect of the model of care (nurses replacing consultant psychiatrists to deliver key functions) helped to overcome initial inertia with regard to scaling up the service. This could be understood in terms of a number of areas of NPT. Most likely, though, it contributed over the course of the two years to less integration between secondary and primary care compared to the Gnosall approach, and, hence, to frustration with regard to key areas of how the model operated. In terms of implications for future studies of scaling up of promising integration services, it points to the need for a longitudinal perspective on how the constructs of NPT are enacted in sites, rather than assuming an analysis at one point in time provides insights into dynamic processes.

With its components focused on collective endeavour NPT can be helpful in focusing on the relational aspects of implementation as well as technical aspects, the latter sometimes seen as the hard, crucial elements to manage (such as technologies and roles) at the expense of the softer relationship-based work (Horton et al. 2018). In understanding the scaling up of the integrated dementia care model, seeking to understand the relational aspects was illuminating as, for example, the informal routes for airing frustrations appeared to be crucial in influencing the final decision.

NPT helped to frame understanding of other insights into the experience of the scaling up process and the final decision to cease the dementia service. In terms of the first construct of NPT, coherence, it seems that whilst there was a high degree of coherence about the new service there was too much scope for uncertainty which the governance and organisational structures proved incapable of addressing. The over-arching goal seems to have been understood as improving dementia care, but there was much room for other specific issues to become foci of judgement about the value of service at different times. Understanding the interplay of coherence with reflexive monitoring it appears that within formal processes for evaluating the scaling up of the service, various topics and some informal processes all worked at different times in the reflexive monitoring as some frustrations (such as variability with diagnosis rates and uncertain diagnoses) came to the fore. In relation to these issues the experiences of key practitioners were not contained in agreed and formalised processes of collective participation and reflexive monitoring, and so could not be resolved into collective action to address them. The frustrations in the scaling up of the gaps in primary-secondary integration compared to its higher degree in Gnosall were never really addressed. These related to issues of workforce development (i.e. how the new roles of the ECFs evolved reactively to events) and of decisions about deployment (i.e. the decisions to reply more on nurses than psychiatrists to provide the direct links to primary care). The former, workforce development, could be understood in terms of NPT as part of the reflexive monitoring and 
ongoing collective action to 'correct' aspects of the initial implementation and, although it produced some frustrations these seem to have been resolved through the evolutions and communication. The deployment issue is one that can be seen in terms of NPT as a failure to engage all significant actors in the collective action of the new model.

The use of the scaling up as a test of new governance arrangements was also never explicit or resolved. The complexity of the organisational arrangements and existing boundaries between them and individual practitioners made resolution difficult and added to frustrations. Whilst the GP interviewed felt the new service was overall a good one and worked, the inability to get the new organisational arrangements to work, especially to reduce variability in diagnostic rates, was a source of frustration for him and, as we understood it, for others with a commissioning perspective on the pilot. In these respects it is helpful to think of complexity in NPT investigations of scaling up of integrated services as a feature of the systems into which the intervention is being placed (Hawe, Shiell \& Riley 2004), as much as of the model of care.

It is interesting to note that the emphasis in judging the scaling up of the service did not appear to be explicitly on improving post-diagnostic support, which had been a significant criterion in the rationale to develop the model in Gnosall. In making the final judgment about the scaling up, less emphasis seems to have been placed on feedback from patients and carers, who reported liking the new model of care. Patient and carer feedback were perhaps a key outcome of the broad understanding of the goal of the scaling up, yet does not seem to have been fully defined or held as a determining factor in reflexive monitoring.

For future NPT studies of scaling up of integrated care services another feature of these complex environments that would need attention is the many roles that individuals can have in them. Each individual role can have varying degrees of agency with regard to implementation processes with regard to the several roles they may have. In these case study sites, GPs, for example, could be commissioners deciding on the model of care to adopt, Federation representatives tasked with agreeing the detailed form of operationalisation, frontline practitioner participants in the new service, and recipients of some of the service provided by others (i.e. ECFs and secondary care colleagues). This may be a common feature of the complexity of integration and does not make it easy to unpick how the agency of individuals works with regard to (non)routinisation.

Closely connected with this issue is that of understanding the structural aspects of scaling up in relation to agency. This is an ongoing debate with regard to NPT in general but may be more so given the complex organisational arrangements inherent in most integration endeavours. Clarke et al. (2013) critique NPT for overly focusing on (individual and collective) agency at the expense of local and external structural factors, although evolutions of NPT have sought to engage with this issue (May 2013; May et al. 2018). This would be something to be particularly attentive to in future applications of NPT to understanding integration. 
From our experience of applying NPT to the case study here, there are challenges with trying to apply the constructs to data collection and analysis, as found in other studies (May et al. 2018). Given that constructs in NPT are intended to work together to explain complex social processes, it can be difficult to assign phenomena in a complex context to only one of the four constructs, something experienced in other work using NPT (McEvoy et al. 2018). Understanding interactions of the constructs of NPT in a study is helpful, but also poses methodological challenges. These include the detailed place of NPT in organising data collection and analysis. As noted, NPT has been used in a variety of ways with regard to this in previous studies. More experience of its application to integration and scaling up studies would help us to understand the merits and challenges of different approaches.

Finally, it is arguable that many of the insights from this study could have come to light even if NPT had not been applied and more general discussion of the experiences of the programme had been sought in, for example, the interviews. NPT helps to ensure, though, that studies are sensitised to particular issues and allows for comparison of them across studies. If they are all understood using the same theoretical perspective, we might begin, for example, to better understand the relative importance of factors in integration scaling up processes.

\section{Conclusion}

We used the opportunity of a planned scaling up of a new integrated care model, a primary care-based dementia service that we have previously examined in detail, to explore the utility of Normalization Process Theory in helping understand this process. We must stress that this should not be seen as an evaluation of the scaling up as we have not been able to triangulate perspectives and data over a long enough period. Crucially, we lacked secondary care perspectives and sufficient interviewees to provide data on some critical aspects of the scaling up. Our specific discussions about the experiences and decisions in the two CCGs are tentative, but we believe provide helpful understanding of how NPT could be used in future work on the scaling up of integrated health and care services.

From this exploratory investigation of the use of NPT, we assert that there are reasons to persist with applying NPT in further studies of scaling up integrated care models. The first is that the methodological challenges can only be addressed through more experience of using the approach in the context of understanding scaling up of integrated care services. The second is that NPT potentially provides a framework to develop more consistency in evaluating the scaling up of integrated care. From this consistency we might be able to develop more robust evidence across contexts that enable us to begin to generalise beyond individual evaluations, and be better placed to helpfully guide the practice of managing scaling up programmes of models of integrated care. 
Whilst personal relationships are important to understanding the success of many collaborative and integrated care models (King et al. 2017; NAO 2017) leaving analysis at that level would not help to address the challenge of scaling up. Some have argued that to support public servants to deliver better services and integration we need to focus on a 'craft' perspective to this work as much as a scientific or managerial one (Dickinson 2014). The craft of integration cannot be reduced to a linear model of implementing a scientific or managerial knowledge base. Yet a craft can also be closely defined in many details, even if it is not reduced to that definition of practices, nor removed from the attentive, contextual and skilful application of the craft. With an insightful theoretical perspective to scaling up models of integration we would hope to add clarity to what the integration craft practitioner has to be attentive to.

\section{References}

Ahmadi-Abhari S, Guzman-Castillo M, Bandosz P, Shipley MJ, Muniz-Terrera G, SinghManoux A, Kivimäki M, Steptoe A, Capewell S, O’Flaherty M \& Brunner EJ (2017) Temporal trend in dementia incidence since 2002 and projections for prevalence in England and Wales to 2040: modelling study. BMJ, 358, p.j2856

Ajzen I (1991) 'The Theory of Planned Behavior', Organizational Behavior and Human Decision Processes 50: 179-211

Banks R \& Gask L (2008) It's time to talk: rekindling the relationship with primary care. Advances in Psychiatric Treatment, vol 14, no 2, pp 84-5

Cameron A, Lart R, Bostock L \& Coomber C (2012) Factors that promote and hinder joint and integrated working between health and social care services. Research Briefing 41. London: Social Care Institute for Excellence

Clark M, Moreland N, Greaves I, Greaves N \& Jolley D (2013) Putting personalisation and integration into practice in primary care. Journal of Integrated Care, 21(2), pp.105-120

Clarke DJ, Godfrey M, Hawkins R, Sadler E, Harding G, Forster A, McKevitt C, Dickerson J, Farrin A (2013) Implementing a training intervention to support caregivers after stroke: a process evaluation examining the initiation and embedding of programme change. Implement Sci. 8(1):96.

Collins B (2018) Adoption and spread of innovation in the NHS. London: The King's Fund Cornwell J (2012) The care of older people with complex needs. London: The King's Fund. https://www.kingsfund.org.uk/sites/default/files/field/field publication file/the-care-offrail-older-people-with-complex-needs-mar-2012.pdf (Accessed 21.10.18) 
Coupe N, Anderson E, Gask L, Sykes P, Richards DA \& Chew-Graham C (2014) Facilitating professional liaison in collaborative care for depression in UK primary care; a qualitative study utilising normalisation process theory. BMC family practice, 15(1), p.78.

Cresswell KM, Worth A \& Sheikh A (2010) Actor-Network Theory and its role in understanding the implementation of information technology developments in healthcare. BMC Medical Informatics and Decision Making, 10:67 http://www.biomedcentral.com/1472-6947/10/67

Damschroder $\amalg$ (2020) Clarity out of chaos: Use of theory in implementation research. Psychiatry Research, 283, p.112461

Department of Health (DH) (2009) Living well with dementia: a national dementia strategy. London: $\mathrm{DH}$

Department of Health (2012) Prime Minister's challenge on dementia : delivering major improvements in dementia care and research by 2015. London: DH

Department of Health (2015) Prime Minister's challenge on dementia 2020. London: DH Dickinson $\mathrm{H}$ (2006) The evaluation of health and social care partnerships: an analysis of approaches and synthesis for the future. Health \& social care in the community, 14(5), pp.375-383

Dickinson $\mathrm{H}$ (2014) Making a reality of integration: less science, more craft and graft. Journal of integrated Care, 22:5/6, 189-96

Donegan K, Fox N, Black N, Livingston G, Banerjee S, \& Burns A (2017) Trends in diagnosis and treatment for people with dementia in the UK from 2005 to 2015: a longitudinal retrospective cohort study. The Lancet Public Health, 2(3), e149-e156.

Erens B, Wistow G, Mounier-Jack S, Douglas N, Jones L, Manacorda T \& Mays N (2016) Early evaluation of the integrated care and support pioneers programme. London: Policy Innovation Research Unit

Evans RE, Craig P, Hoddinott P, Littlecott H, Moore L, Murphy S, O'Cathain A, Pfadenhauer L, Rehfuess E, Segrott J, Moore G (2019) When and how do 'effective'interventions need to be adapted and/or re-evaluated in new contexts? The need for guidance. J Epidemiol Community Health. June, Vol 73 No 6, pp. 481-2

Exworthy M, Powell M \& Glasby J (2017) The governance of integrated health and social care in England since 2010: great expectations not met once again? Health Policy. Nov 1;121(11):1124-30 
Ferrara L \& Moro G (2016) A theory-driven evaluation of Integrated Health and Social Care Programmes in the Apulia Region. International Journal of Integrated Care. 16(6):A107. DOI: http://doi.org/10.5334/ijic.2655

Finch, T. 2008 'Teledermatology for chronic disease management: coherence and normalization', Chronic Illness 4(2): 127-134.

Foresight (2016) Future of an Ageing Population. London: Government Office for Science Gask L, Rogers A, Campbell S \& Sheaff R (2008) Beyond the limits of clinical governance? The case of mental health in English primary care. BMC Health Services Research, 8(1), p.63

Gilburt H \& Peck E with Ashton B, Edwards N \& Naylor C (2014) Service transformation: lessons from mental health. London: The King's Fund

Goddard M \& Mason A R (2016) Integrated Care: A Pill for All Ills? Int J Health Policy Manag 2016, 5(x), 1-3. Doi: 10.15171/ijhpm.2016.111

Goodwin N (2013) How do you build programmes of integrated care? The need to broaden our conceptual and empirical understanding. International Journal of Integrated Care, 13(3)

Greaves I, Greaves N, Walker E, Greening L, Benbow SM \& Jolley D (2015) Gnosall primary care memory clinic: eldercare facilitator role description and development. Dementia, 14(4), pp.389-408

Greenhalgh T, Robert G, Macfarlane F, Bate P, Kyriakidou O. (2004) Diffusion of innovations in service organizations: systematic review and recommendations. Milbank Q., 82:581-629

Greenhalgh T, Wherton J, Papoutsi C, Lynch J, Hughes G, A'Court C, Hinder S, Fahy N, Procter R \& Shaw S (2017) Beyond adoption: a new framework for theorizing and evaluating nonadoption, abandonment, and challenges to the scale-up, spread, and sustainability of health and care technologies. Journal of Medical Internet Research, 19(11)

Ham C \& Walsh N (2013) Making integrated care happen at scale and pace. London: King's Fund

Hanbury A, Wallace L \& Clark M (2009) Use of a time series design to test effectiveness of a theory-based intervention targeting adherence of health professionals to a clinical guideline." British Journal of Health Psychology 14, no. 3: 505-518.

Hawe P, Shiell A \& Riley T (2004) Complex interventions: how far 'out of control' should a randomised controlled trial be? BMJ 328:1561-63

Health \& Social Care Information Centre (HSCIC) (2015) Quality Outcomes Framework (QOF) recorded dementia diagnoses. December 2014. London: HSCIC 
Hawkins J (2015) Models of Dementia Assessment and Diagnosis: Indicative Cost Review. London: NHS Improving Quality

Horton T, Illingworth J, Warburton W (2018) The spread challenge: how to support the successful uptake of innovations and improvements in health care. London: The Health Foundation

House of Commons Health Committee (2014) Managing the care of people with long term conditions, second report of session 2014/15. London: The Stationery Office

Humphries R (2015) Integrated health and social care in England-Progress and prospects. Health Policy. 119(7), pp.856-859

Jeffcott S (2014) The spread and sustainability of quality improvement in healthcare: a resource to increase understanding of the 10 key factors underpinning successful spread and sustainability of quality improvement in NHS Scotland. Healthcare Improvement Scotland.

Jolley D, Greaves I \& Clark M (2012) Memory clinics and primary care: not a question of either/or. BMJ. Vol. 344, No. jun25, pp. e4286-e4286)

Jolley D, Greaves I, Greaves N and Greening L (2010) Three tiers for a comprehensive regional memory service. Journal of Dementia Care 18 (1) 26-29

King N, Bravington A, Brooks J, Melvin J \& Wilde D (2017) “Go make your face known": Collaborative working through the lens of personal relationships. International Journal of Integrated Care, 17(4)

Kitson, A.L., Rycroft-Malone, J., Harvey, G., McCormack, B., Seers, K. and Titchen, A., 2008. Evaluating the successful implementation of evidence into practice using the PARiHS framework: theoretical and practical challenges. Implementation science, 3(1), p.1.

Knapp M, Black N, Dixon J, Damant J, Rehill A \& Tan S (2014) Independent assessment of improvements in dementia care and support since 2009. London: Policy Innovation Research Unit and the NIHR School for Social Care Research

Latour B (2005) Reassembling the Social: An Introduction to Actor Network Theory. Oxford: Oxford University Press

Leutz W (2005) Reflections on integrating medical and social care: five laws revisited. Journal of Integrated Care, 13(5), pp.3-12.

Livingston G, Sommerlad A, Orgeta V, Costafreda SG, Huntley J, Ames D, Ballard C, Banerjee S, Burns A, Cohen-Mansfield J \& Cooper C (2017) Dementia prevention, intervention, and care. The Lancet, 390(10113), pp.2673-2734. 
May C (2006) A rational model for assessing and evaluating complex interventions in health care. BMC Health Services Research. 6, 86

May C (2013) Towards a general theory of implementation. Implement Sci. 8(1):18

May CR, Cummings A, Girling M, Bracher M, Mair FS, May CM, Murray E, Myall M, Rapley T, Finch $T$ (2018) Using Normalization Process Theory in feasibility studies and process evaluations of complex healthcare interventions: a systematic review. Implementation Science. Dec 1;13(1):80.

May C \& Finch T (2009) Implementing, embedding and integrating practices: an outline of normalization process theory. Sociology, 43:3, 535-54. DOI: 10.1177/0038038509103208

May C, Finch T, Mair F, Ballini L, Dowrick C, Eccles M, Gask L, MacFarlane A, Murray E, Rapley T, Rogers A, Treweek S, Wallace P, Anderson G, Burns J, Heaven B (2007) Understanding the implementation of complex interventions in health care: the normalization process model. BMC Health Services Research 7 (148)

May C, Sibley A \& Hunt K (2014) 'The nursing work of hospital-based clinical practice guideline implementation: An explanatory systematic review using Normalisation Process Theory'. International Journal of Nursing Studies. 51(2), pp. 289-299.

doi:10.1016/j.ijnurstu.2013.06.019

McEvoy R, Ballini L, Maltoni S, O'Donnell CA, Mair FS \& MacFarlane A (2014) A qualitative systematic review of studies using the normalization process theory to research implementation processes. Implementation Science, 9(1), p.2.

Medical Research Council (2008) Developing and evaluating complex interventions: new guidance. MRC, London

Meeuwsen EJ, Melis RJF, Van Der Aa GCHM, Golüke-Willemse GAM, De Leest BJM, Van Raak FHJM, et al. (2012) Effectiveness of dementia follow-up by memory clinics or general practitioners: randomised controlled trial. BMJ. 344:e3086.

Mukadam N, Livingston G, Rantell K, et al. (2014) Diagnostic rates and treatment of dementia before and after launch of a national dementia policy: an observational study using English national databases. BMJ Open;4:e004119. doi:10.1136/bmjopen-2013- 004119

Moore GF \& Evans RE (2017)What theory, for whom and in which context? Reflections on the application of theory in the development and evaluation of complex population health interventions. SSM-population health. Dec 1;3:132-5.

National Audit Office (2017) Health and social care integration. London National Audit Office 
Naylor C \& Charles A (eds.) (2018) Developing new models of care in the PACS vanguards: a new national approach to large-scale change? London: King's Fund

NHS England Sustainable Improvement Team (nd) The change model guide. London: NHS England

Nilsen P (2015) Making sense of implementation theories, models and frameworks. Implementation Science. 10(1), DOI 10.1186/s13012-015-0242-0

Oliver D, Foot C \& Humphries R (2014) Making our health and care systems fit for an ageing population. London: King's Fund

Ovretveit J. (2018) Learning about improvement to address global health and healthcare challenges-lessons and the future. International Journal for Quality in Health Care, 30(suppl_1), 37-41.

Ovretveit J, Dolan-Branton L, Marx M, Reid A, Reid J, \& Agins B (2018) Adapting improvements to context: when, why and how? International Journal for Quality in Health Care, 30(suppl 1), 20-23.

Parliamentary and Health Service Ombudsman (2016) A report of an investigation of unsafe discharges from hospital https://www.ombudsman.org.uk/sites/default/files/page/A\%20report\%20of\%20investigati ons\%20into\%20unsafe\%20discharge\%20from\%20hospital.pdf (Accessed 21.10.18)

Pawson R \& Tilley N (1997) Realistic evaluation. London, California and New Delhi: Sage.

Royal College of Psychiatrists (2011) Report of the national audit of dementia care in general hospitals 2012-13. London: Healthcare Quality Improvement Partnership.

Sadler E, Sandall J, Sevdalis N \& Wilson D (2018)The contribution of implementation science to improving the design and evaluation of integrated care programmes for older people with frailty. Journal of Integrated Care. 1476-9018, DOI 10.1108/JICA-07-2018-0048.

Shiell-Davis K (2015) Scaling-up innovations. Glasgow: What Works Scotland. Available at: http://whatworksscotland.ac.uk/wp-content/uploads/2015/06/WWS-EB-evidence-reviewScaling-Up-Innovations-June-2015.pdf

Stokes J, Checkland K \& Kristensen SR (2016) Integrated care: theory to practice. Journal of Health Services Research \& Policy, 21(4), pp.282-285

Stirman SW, Miller CJ, Toder K \& Calloway A (2013) Development of a framework and coding system for modifications and adaptations of evidence-based interventions. Implementation Science. 8:65 
Tazzyman A, Ferguson J, Hillier C, Boyd A, Tredinnick-Rowe J, Archer J, de Bere SR, Walshe K (2017) The implementation of medical revalidation: an assessment using normalisation process theory. BMC Health Services Research. Dec 1;17(1):749.

Van der Klauw D, Molema H, Grooten L. \& Vrijhoef H (2014) Identification of mechanisms enabling integrated care for patients with chronic diseases: a literature review. International Journal of Integrated Care, 14(3).

Willis CD, Riley BL, Stockton L, Abramowicz A, Zummach D, Wong G, ... \& Best A (2016) Scaling up complex interventions: insights from a realist synthesis. Health research policy and systems, 14(1), 88.

World Health Organization (WHO) (2018) Nine steps for developing a scaling-up strategy. Geneva: WHO

World Health Organization (WHO) (2012) Dementia: a public health priority. Geneva: WHO 